\title{
Regulatory Mechanisms Governing Synthesis of the Enzymes for Tryptophan Oxidation by Pseudomonas fluorescens
}

\author{
By N. J. PALLERONI AND R. Y. STANIER \\ Department of Bacteriology, University of California, Berkeley, \\ California (U.S.A.)
}

(Received 17 December 1963)

\begin{abstract}
SUMMARY
Both co-ordinate and sequential inductions govern the synthesis of the enzymes required for the oxidative dissimilation of L-tryptophan by a strain of Pseudomonas fluorescens. The first two enzymes of the sequence, tryptophan pyrrolase and formylkynurenine formamidase, are induced co-ordinately by $\mathbf{L}$-kynurenine, the product of their successive action on L-tryptophan; L-tryptophan itself is not an inducer. Both these enzymes are present at low concentrations in uninduced organisms, so that inducer is generated endogenously when such organisms are exposed to an exogenous supply of L-tryptophan. L-Kynurenine also induces formation of the third enzyme of the sequence, kynureninase, which is not detectable in uninduced bacteria. Although it is elicited by the same inducer, synthesis of kynureninase is not co-ordinate with the syntheses of pyrrolase and formamidase; the induction of kynureninase can accordingly be considered as the first sequential inductive step in the pathway. It is immediately followed by another sequential inductive step: the synthesis of anthranilic acid oxidase, elicited by anthranilic acid, which is formed from kynurenine through the action of kynureninase.
\end{abstract}

\section{INTRODUCTION}

Tryptophan can serve as sole source of carbon and energy for the aerobic growth of many bacteria belonging to the Pseudomonas group. The oxidative dissimilation of tryptophan is catalysed by special sequences of enzymes, the physiological role of which is to convert this heterocyclic substrate to aliphatic fragments that can enter the central pathways of cellular intermediary metabolism. The initial attack is mediated by tryptophan pyrrolase and formylkynurenine formamidase, and results in conversion of L-tryptophan to L-kynurenine (Suda, Hayaishi \& Oda, 1949; Stanier \& Tsuchida, 1949; Stanier \& Hayaishi, 1951). The further metabolism of L-kynurenine proceeds through one of two alternative pathways, the so-called 'aromatic' and 'quinoline' pathways (Fig. 1). On the aromatic pathway, a sequence of about seven enzymes operates to convert L-kynurenine into L-alanine, succinylCoA and acetyl-CoA (Hayaishi \& Stanier, 1951; Katagiri \& Hayaishi, 1956). On the quinoline pathway, a different but equally extensive sequence of enzymes catalyses the conversion of L-kynurenine, through a series of quinoline and pyridine derivatives, to glutamic and oxaloacetic acids (Behrman, 1962). Any given Pseudomonas strain capable of extensive oxidation of tryptophan uses either the aromatic or the quinoline pathway (Stanier, Hayaishi \& Tsuchida, 1951). 
Early manometric studies established that tryptophan oxidation is an inducible process, formation of the specific enzymes being elicited by exposure of the cells to tryptophan (Suda et al. 1949; Stanier \& Tsuchida, 1949). It was also observed that induction is grossly sequential: thus, anthranilic acid and kynurenic acid, the first intermediates on the aromatic and quinoline pathways, respectively, do not

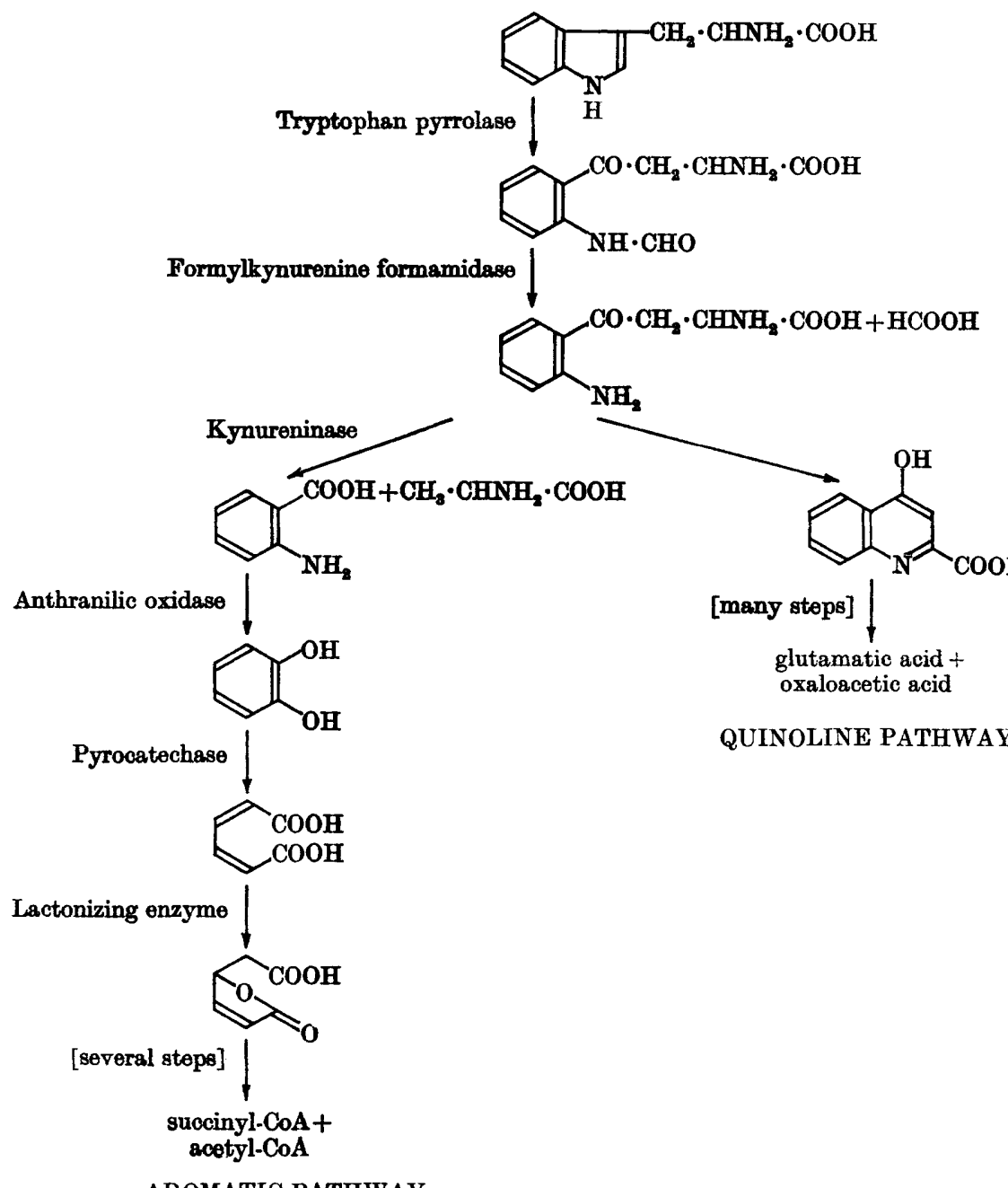

Fig. 1. A condensed metabolic map of the divergent pathways for the oxidative dissimilation of L-tryptophan by pseudomonads, showing the points of action of the enzymes discussed in this paper.

serve as inducers for the enzymes responsible for the initial attack on tryptophan, although they elicit synthesis of the whole series of enzymes operative in the subsequent steps of their respective pathways. The discovery of inductive sequentiality in these and other complex enzymatic sequences among bacteria led to the hypothesis, independently proposed by several workers (Stanier, 1947; Karlsson \& 
Barker, 1948; Suda et al. 1949), that induction proceeds in single sequential steps. According to this hypothesis, each substrate in such a metabolic sequence is at the same time a specific inducer of the enzyme which converts it to the next compound of the sequence; exposure of the cell to a primary inducer-substrate thus triggers an interlocked chain of specific inductions and specific enzymatic step-reactions. The evidence in support of this hypothesis with respect to the inducible systems for the oxidation of tryptophan was extremely fragmentary. Furthermore, one of the first studies of inductive patterns, in a Pseudomonas strain using the quinoline pathway, revealed a striking example of non-sequential induction: kynurenine proved as effective as tryptophan in inducing attack on tryptophan (Stanier \& Tsuchida, 1949). During the past decade, the nature of the inductive and repressive control mechanisms that operate in other types of bacterial metabolic sequences has been extensively explored (Jacob \& Monod, 1961). This has prompted us to re-investigate the mechanism of induction of the enzymes which initiate the dissimilation of $\mathrm{L}^{-}$ tryptophan through the aromatic pathway; the results are reported here.

\section{METHODS}

Biological materials. The bacterium employed was Pseudomonas fluorescens Tr-23, the strain with which the biochemistry of the aromatic pathway was originally elucidated (Hayaishi \& Stanier, 1951). Cultures were grown in defined media containing $\mathrm{Na} \mathrm{K}$ phosphate buffer (0.02 $\mathrm{M}, \mathrm{pH} \mathrm{6.8),} 1000 \mathrm{ml}$.; $\left(\mathrm{NH}_{4}\right)_{2} \mathrm{SO}_{4}, 1.0 \mathrm{~g}$.; Hutner's base (Cohen-Bazire, Sistrom \& Stanier, 1957) $20 \mathrm{ml}$.; and an appropriate oxidizable substrate. Asparagine (0.3\%) was commonly used for the growth of 'uninduced' bacteria (i.e. bacteria not specifically induced for the enzymes of the aromatic pathway). Fully induced bacteria of the wild type were usually grown in the mineral asparagine medium supplemented with $0.1 \%$ L-tryptophan, since preliminary experiments showed that asparagine did not repress synthesis of the enzymes of tryptophan oxidation. Tryptophan and tryptophan derivatives used in media as inducers or substrates were sterilized by filtration and added separately to the autoclaved basal media. Liquid cultures were grown on a mechanical shaker. The temperature of incubation was $30^{\circ}$.

Mutants of Pseudomonas fluorescens strain Tr-23 with specific enzymatic defects in the aromatic pathway were isolated from the parent strain after treatment with the chemical mutagen ethylmethanesulphonate (EMS). A suspension containing approximately $10^{9}$ bacteria of the wild type in $0.033 \mathrm{M}$-phosphate buffer (pH 7.0) was mixed with an equal volume of freshly diluted EMS (approx. $0.25 \mathrm{M}$ ) in phosphate buffer and incubated on the shaker at $30^{\circ}$ for $90 \mathrm{~min}$. About $99.5 \%$ of the bacteria were killed by this treatment. The mixture was then diluted in buffer, and samples containing 50-100 viable bacteria were spread on a series of plates. Two methods were used to detect tryptophan-negative mutants. In the first, primary plates were prepared on mineral asparagine agar. When colonies had developed, replicas were prepared on mineral tryptophan agar. After growth had taken place on the replica plates, tryptophan-negative mutants were detected by visual comparison of the two sets of plates. Subsequently, an even simpler method for detecting such mutants was devised. After treatment with EMS, the survivors were spread on plates of a medium containing $0.1 \% \mathrm{~L}$-tryptophan and $0.01 \%$ asparagine. 
The low concentration of asparagine was not in itself sufficient to allow the growth of colonies to full size, so that mutant clones unable to utilize tryptophan were immediately detected on such plates by the smallness of their colonies. All putative mutants were purified by restreaking on mineral asparagine agar, after which their inability to grow with tryptophan and their genetic stability were controlled by patching on mineral tryptophan agar plates.

Table 1. Spectrophotometric assays for enzymes of the aromatic pathroay as employed with crude bacterial extracts

\begin{tabular}{|c|c|c|c|c|}
\hline Enzyme & Reaction & Principle of assay method & $\begin{array}{l}\text { Wavelength of } \\
\text { measurement } \\
\qquad(\mathrm{m} \mu)\end{array}$ & Reference \\
\hline Pyrrolase & $\begin{array}{l}\text { L-Tryptophan } \rightarrow \\
\text { L-formylkynurenine }\end{array}$ & $\begin{array}{l}\text { Accumulation of kynurenine in } \\
\text { presence of excess of formamidase } \\
\text { and semicarbazide }\end{array}$ & 365 & $\begin{array}{l}\text { Modified from } \\
\text { Tanaka \& Knos } \\
\text { (1958) }\end{array}$ \\
\hline Formamidase & $\begin{array}{l}\text { L-Formylkynurenine } \rightarrow \\
\text { L-kynurenine + formic } \\
\text { acid }\end{array}$ & $\begin{array}{l}\text { Accumulation of kynurenine in } \\
\text { presence of semicarbazide }\end{array}$ & 365 & $\begin{array}{l}\text { Modified from } \\
\text { Knox (1955) }\end{array}$ \\
\hline Kynureninase & $\begin{array}{l}\text { L-Kynurenine } \rightarrow \\
\text { anthranilic acid }+ \\
\text { L-alanine }\end{array}$ & Disappearance of kynurenine & 365 & $\begin{array}{l}\text { Hayaishi \& } \\
\text { Stanier (1952) }\end{array}$ \\
\hline Pyrocatechase & $\begin{array}{l}\text { Catechol } \rightarrow \text { cis, } \\
\text { cis-muconic acid }\end{array}$ & $\begin{array}{l}\text { Accumulation of cis,cis-muconic } \\
\text { acid in presence of EDTA }\end{array}$ & 260 & $\begin{array}{l}\text { G. Hegeman } \\
\text { (unpublished } \\
\text { observations) }\end{array}$ \\
\hline $\begin{array}{l}\text { Lactonizing } \\
\text { enzyme }\end{array}$ & $\begin{array}{l}\text { Cis,cis-muconic acid } \\
\rightarrow \text { muconolactone }\end{array}$ & $\begin{array}{l}\text { Disappearance of cis,cis-muconic } \\
\text { acid }\end{array}$ & 260 & $\begin{array}{l}\text { Sistrom \& Stanif } \\
\text { (1954) }\end{array}$ \\
\hline
\end{tabular}

Mutants were initially screened to determine the site of the block in tryptophan metabolism as follows. Cultures were grown in liquid asparagine medium supplemented with $0 \cdot 1 \%$ L-tryptophan, the cultures were centrifuged, and the ultraviolet absorption spectrum of the supernatant medium was determined. All the early intermediates on the aromatic pathway have distinctive absorption peaks between 230 and $380 \mathrm{~m} \mu$, so that the nature of the intermediate accumulated by many mutants (and, by inference, the blocked enzymatic reaction) could be readily determined. In most cases, the nature of the enzymatic lesion was subsequently confirmed by the enzymatic analysis of cell-free extracts. The initial screening method did not differentiate between pyrrolase-less and formamidase-less mutants, neither of which could attack tryptophan appreciably under the conditions of culture used. These two phenotypes could, accordingly, be distinguished only by enzymatic analysis.

The experiments with mutants that are reported in this paper were performed with three phenotypes: pyrrolase-less $\left(\mathrm{Py}^{-}\right)$; formamidase-less $\left(\mathrm{Fo}^{-}\right)$; and kynureninaseless $\left(\mathrm{Ky}^{-}\right)$. The selection procedure also yielded many mutants blocked at later steps in the aromatic pathway, and specifically lacking either anthranilic acid oxidase, pyrocatechase, or lactonizing enzyme.

Enzymatic methods. Bacteria were harvested by centrifugation, washed once with $0.033 \mathrm{M}$-phosphate buffer ( $\mathrm{pH} 6 \cdot 8$ ), and stored as frozen pellets until the time of extraction. The frozen bacteria were resuspended with about three times their

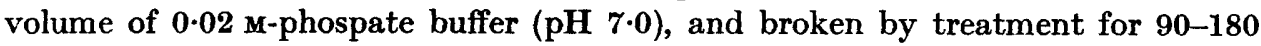
sec. in the MSE ultrasonic disintegrator. The resulting extracts were centrifuged at 
$20,000 \mathrm{~g}$ for $30 \mathrm{~min}$., and the sediment was discarded. The supernatant extract, with a protein content between 12 and $20 \mathrm{mg}$. $/ \mathrm{ml}$. as measured by the biuret method, was used for the performance of assays.

Five specific enzymes of the aromatic pathway were assayed in such crude extracts by spectrophotometric methods, as outlined in Table 1. The assay methods used for tryptophan pyrrolase and formylkynurenine formamidase depend on the conversion of these substrates to kynurenine, which has a major absorption peak at $365 \mathrm{~m} \mu$. The published procedures (Knox, 1955; Tanaka \& Knox, 1958) are satisfactory only with preparations that are essentially free of kynureninase. This enzyme is normally very active in extracts prepared from tryptophan-induced organisms of Pseudomonas fluorescens Tr-23, but its activity can be virtually abolished by pre-incubation of the extract with semicarbazide. The effects of semicarbazide on pyrrolase and formamidase function could be directly evaluated using crude extracts from induced $\mathrm{Ky}^{-}$mutants, which contain high activities of these two enzymes, but lack kynureninase. Semicarbazide does not appreciably affect pyrrolase function. The rate of formamidase action is, however, rapidly decreased in the presence of semicarbazide, no doubt as a consequence of the combination of semicarbazide with the substrate. Nevertheless, the assay of formamidase can be performed in the presence of semicarbazide by measuring the rate of the reaction during the 1st min. after substrate addition. Accordingly, semicarbazide at a concentration of $5 \times 10^{-3} \mathrm{M}$ was routinely used in the assays of pyrrolase and formamidase, being added to the extract $5 \mathrm{~min}$. before substrate addition. The published assay method for tryptophan pyrrolase (Tanaka \& Knox, 1958) calls for supplementation of the assay mixture with formamidase, to ensure the immediate conversion of the reaction-product, formylkynurenine, to kynurenine. This usually proved unnecessary here with the bacterial extracts, since formamidase was present in excess of pyrrolase. Extracts of the Fo- phenotype were, however, completely devoid of formamidase. In this case, pyrrolase was assayed by measuring appearance of the formylkynurenine peak at $315 \mathrm{~m} \mu$, control experiments having shown that rates so measured were indistinguishable from rates measured in the presence of an excess of added formamidase.'

Chemicals. L- $\alpha$-Amino- $\gamma$-hydroxy- $\gamma$-(2-aminophenyl)-butyric acid, which will be referred to hereafter as $\gamma$-hydroxy-L-kynurenine, was prepared by treatment of 1.54 m-mole L-kynurenine sulphate in $25 \mathrm{ml}$. of 0.006 M-phosphate buffer $(\mathrm{pH} \mathrm{7.0})$ with a fourfold molar excess of sodium borohydride at room temperature. The reduction was followed spectrophotometrically by the disappearance of the kynurenine peak at $365 \mathrm{~m} \mu$, and was complete in about $60 \mathrm{~min}$. The reaction mixture was passed through Amberlite IR 120 in the $\mathbf{H}^{+}$form, and, after the column had been washed with water, the $\gamma$-hydroxy-L-kynurenine was eluted with $5 \mathrm{~N}$-ammonia. The eluate was concentrated under reduced pressure, and the product crystallized from water before use.

Pure D-kynurenine was prepared from the racemic mixture through selective oxidation of the L-isomer by tryptophan-induced organisms of the wild type. The course of the reaction was followed spectrophotometrically, by measuring the decrement of absorbancy at $365 \mathrm{~m} \mu$, which proceeded to the theoretical value. The bacteria were removed by centrifugation, and the resultant solution of $\mathbf{D}$-kynurenine was filter-sterilized and used directly for experiments. The completeness of the 
resolution was confirmed by treating a sample with a large excess of bacterial kynureninase, which is specific for the $\mathrm{L}$-isomer and is not inhibited by the $\mathrm{D}$-isomer. Such treatment produced no change in the absorbancy at $365 \mathrm{~m} \mu$.

Commercial D-tryptophan, found to be contaminated by traces of the L-isomer, was completely resolved by treatment in similar fashion with tryptophan-induced organisms of the wild type, and was subsequently recrystallized several times from water.

Commercial L-formylkynurenine, found to be contaminated with L-kynurenine, was repurified by treatment with a suspension of organisms of the $\mathrm{Fo}^{-}$mutant preinduced with kynurenine, and therefore able to oxidize L-kynurenine but not Lformylkynurenine. The course of the oxidation was followed by measurement of absorbancies at $320 \mathrm{~m} \mu$ (formylkynurenine peak) and $365 \mathrm{~m} \mu$ (kynurenine peak).

\section{RESULTS}

\section{Inductive patterns of the roild type}

As a preliminary to enzyme studies, the rates of oxygen uptake at the expense of L-tryptophan, L-kynurenine and anthranilic acid by resting organisms of the wildtype Pseudomonas fluorescens $\mathbf{T r}-23$ after exposure to various inducers were determined. Exposure to either L-tryptophan or L-kynurenine established the same respiratory pattern; both these compounds, as well as anthranilic acid, were immediately oxidized at a high and steady rate. Organisms exposed to anthranilic acid immediately and rapidly oxidized this substrate, but could not initially oxidize either tryptophan or kynurenine. 'Uninduced' bacteria, grown on asparagine alone, did not immediately respire with tryptophan, kynurenine or anthranilic acid.

The specific activities of five enzymes operative in the pathway of tryptophan oxidation were then determined on extracts prepared from uninduced bacteria (grown with asparagine alone), and from bacteria grown in the same medium supplemented singly with L-tryptophan, L-kynurenine, anthranilic acid, and D-tryptophan (Table 2). All five enzymes are present at relatively high specific activities (ranging from 20 to $150 \mathrm{~m} \mu$ moles of substrate utilized/min./mg. protein) in extracts of bacteria grown with either L-tryptophan or L-kynurenine. The enzymatic patterns induced by these two compounds were indistinguishable, both quantitatively and qualitatively. It should be specifically noted that the first two enzymes of the sequence, pyrrolase and formamidase, were fully induced by L-kynurenine, the product of their action on L-tryptophan.

Extracts from uninduced (asparagine-grown) bacteria did not contain measurable activities of kynureninase, pyrocatechase, or lactonizing enzyme. The values given in Table 2 accordingly represent the maximal possible activities, calculated from the sensitivity of the specific assay methods; they range from less than 0.01 to $0.2 \%$ of the activities present in tryptophan-induced bacteria. The first two enzymes in the pathway (pyrrolase, formamidase) were, however, readily detectable in extracts of asparagine-grown bacteria. In nine separate analyses of extracts prepared from asparagine-grown bacteria, the specific activity of pyrrolase ranged from 0.26 to 0.7 and, of formamidase, from $2 \cdot 1$ to $4 \cdot 2$.

Extracts of bacteria induced with anthranilic acid did not contain detectable kynureninase activity, and the activities of pyrrolase and formamidase were within 
the range characteristic for asparagine-grown bacteria. Both pyrocatechase and lactonizing enzyme were present at concentrations comparable with those in tryptophan-induced bacteria. Also presented in Table 2 are data obtained for an extract from bacteria grown in the presence of D-tryptophan, which is not attacked by Pseudomonas fluorescens strain Tr-23. The enzymatic constitution of such bacteria is indistinguishable from that of asparagine-grown bacteria.

\section{Table 2. Induction of enzymes of the aromatic pathway in Pseudomonas fluorescens strain $\mathrm{Tr}-23$ by tryptophan and some of its derivatives}

P. fluorescens Tr-23 was grown for $12 \mathrm{hr}$ in liquid mineral asparagine medium, either unsupplemented or specifically supplemented with the indicated compounds, at an initial concentration of $0.05 \mathrm{M}$. The activities were determined on cell-free extracts, and are expressed as $\mathbf{m} \mu \mathrm{moles}$ substrate decomposed/min./mg. protein.

Additions to basal medium

None L-tryptophan D-tryptophan L-kynurenine Anthranilic

Enzyme

Pyrrolase

Formamidase

Kynureninase

Pyrocatechase

Lactonizing enzyme m $\mu$ moles substrate decomposed/min./mg. protein

\begin{tabular}{crccc}
\hline $0 \cdot 4$ & 21 & $0 \cdot 4$ & 20 & $0 \cdot 3$ \\
3 & 51 & 4 & 53 & 3 \\
$\leqslant 0 \cdot 1^{*}$ & 74 & $\leqslant 0 \cdot 1^{*}$ & 60 & $\leqslant 0 \cdot 1^{*}$ \\
$\leqslant 0 \cdot 05^{*}$ & 71 & $\leqslant 0 \cdot 05^{*}$ & 70 & 52 \\
$\leqslant 0 \cdot 01^{*}$ & 144 & $\leqslant 0 \cdot 01^{*}$ & 130 & 118
\end{tabular}

* Activity not detectable. The value given represents the possible maximum, in view of the estimated threshold sensitivity of the assay method employed.

The results of the enzymatic analyses are in good general accord with the gross inductive patterns revealed by the respiratory activities of intact bacteria. The one unexpected finding was the presence of low concentrations of pyrrolase and formamidase in asparagine-grown bacteria. The action of pyrrolase, but not of formamidase, results in oxygen consumption. It can be calculated that the rate of oxygen uptake at the expense of tryptophan caused by the amount of pyrrolase in uninduced bacteria is negligible relative to the endogenous rate of respiration. Hence manometric analysis is too coarse a tool to detect the presence of this enzyme in such bacteria.

Either the primary substrate, L-tryptophan, or the second intermediate in the pathway, L-kynurenine, can induce all the enzymes of the aromatic pathway. However, since uninduced bacteria already possess the first two enzymes of the pathway at low concentrations, the provision of an exogenous supply of L-tryptophan immediately permits an endogenous synthesis of $L$-kynurenine. Hence these experiments do not permit the conclusion that L-tryptophan has an intrinsic inductive function, distinct from the indirect inductive function that it undoubtedly possesses by virtue of serving as a metabolic precursor of L-kynurenine. The non-metabolizable D-isomer of tryptophan is completely devoid of inductive function. Anthranilic acid cannot induce synthesis of any of the first three enzymes of the pathway, all of which are induced by its immediate metabolic precursor, L-kynurenine. 
The gross kinetics of induction in the wild type

A culture of the wild-type Pseudomonas fluorescens Tr-23 in the course of exponential growth at the expense of asparagine was transferred to a flask of the same medium, supplemented with 0.05 M-L-tryptophan. Samples of the growing culture were removed after 30,90, and $180 \mathrm{~min}$. The bacteria were harvested and extracted, and the activities of pyrrolase, formamidase, kynureninase, pyrocatechase, and lactonizing enzyme determined in the extracts (Fig. 2). With respect to their initial rates of synthesis, the five enzymes clearly fell into two distinct groups. The first three enzymes were rapidly synthesized; their specific activities increased markedly 30 min. after exposing the bacteria to tryptophan. The last two enzymes, which operate below the level of anthranilic acid in the pathway, were synthesized only

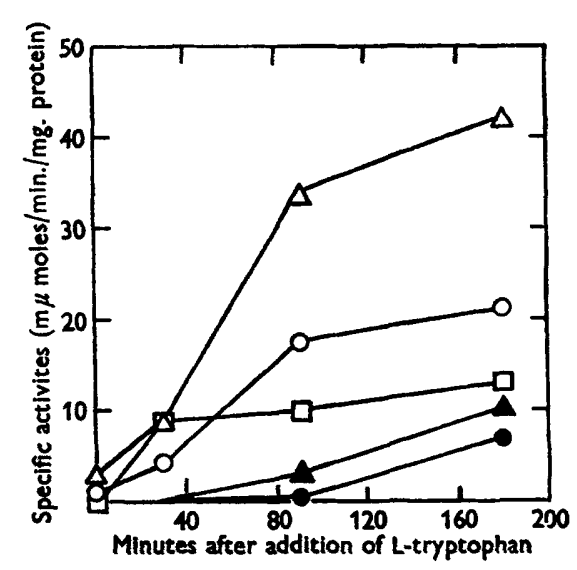

Fig. 2

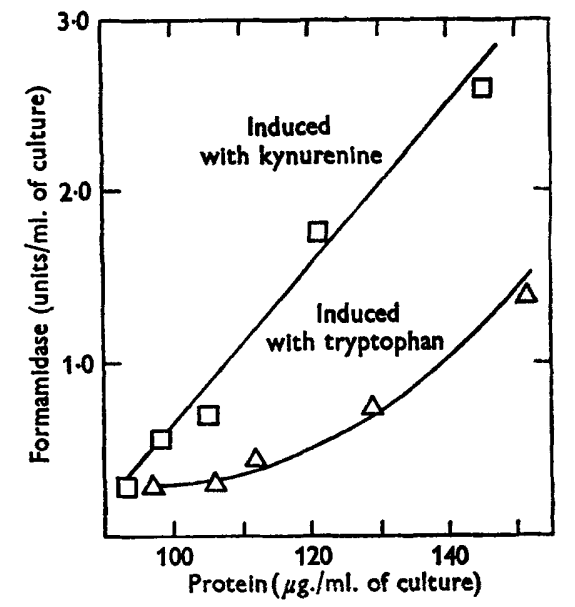

Fig. 3

Fig. 2. The gross kinetics of synthesis of five enzymes of the aromatic pathway, following induction of cells by L-tryptophan during growth in a mineral asparagine medium. $\mathrm{O}-\mathrm{O}$, Pyrrolase; $\triangle \longrightarrow \triangle$, formamidase; $\square-\square$, kynureninase; $-\longrightarrow$, pyrocatechase; $\Delta \longrightarrow \Delta$, lactonizing enzyme.

Fig. 3. Differential rates of synthesis of formamidase by the wild type of Pseudomonas fluorescens, following induction with L-kynurenine and with L-tryptophan.

after a considerable lag, being undetectable after $30 \mathrm{~min}$. of exposure to tryptophan, and present at very low values (relative to the first three enzymes) even after 90 min. A parallel experiment, in which L-kynurenine was used as inducer in place of L-tryptophan, gave comparable results.

The general interpretation of these experiments seems evident. Effective inducer concentrations for the synthesis of pyrrolase, formamidase, and kynureninase were established in the bacteria very shortly after exposure to tryptophan or kynurenine; but effective inducer concentrations for the synthesis of pyrocatechase and lactonizing enzyme were produced only as a result of metabolic transformations of kynurenine which required a considerable time. This suggests that one or more sequential inductive steps intervened between the synthesis of kynureninase and the syntheses of pyrocatechase and lactonizing enzyme. 
The severity of the transient imbalance between the enzymes of the aromatic pathway that follows the onset of induction implies that, if the enzymatic constitution of the bacteria could be stabilized after brief induction, such organisms might metabolize tryptophan or kynurenine with a massive accumulation of the first sequential inducer-substrate in the pathway after kynurenine. To test this hypothesis, bacteria which had been permitted to grow for $60 \mathrm{~min}$. in the presence of 0.05 M-L-tryptophan were subjected to ultraviolet irradiation sufficient to block further protein synthesis. The irradiated bacteria were washed and resuspended in buffer, and their ability to metabolize tryptophan was determined. They oxidized tryptophan with a very low total oxygen uptake, accompanied by a virtually quantitative conversion of tryptophan to anthranilic acid, as determined by spectrophotometric examination of the supernatant medium. The dose of irradiation used did not decrease the rate or extent of tryptophan oxidation by fully induced organisms. An unirradiated suspension of the partly induced organisms oxidized tryptophan to completion under the conditions of a manometric experiment, presumably because synthesis of the later enzymes in the pathway occurred during the course of this oxidation. This experiment indicates that anthranilic acid oxidase is sequentially induced by its substrate, anthranilic acid. Additional sequential inductive steps may intervene before the synthesis of pyrocatechase and lactonizing enzyme, but we have not further examined this aspect of the problem.

\section{Inductive responses of mutants with early blocks in the aromatic pathroay}

Five mutants with early and absolute blocks in the aromatic pathway were isolated. Two were pyrrolase-less $\left(\mathrm{Py}^{-}\right)$, one formamidase-less $\left(\mathrm{Fo}^{-}\right)$, and two kynureninase-less $\left(\mathrm{Ky}^{-}\right)$. The specific activities of the first three enzymes of the pathway in extracts of uninduced (asparagine-grown) and specifically induced organisms of these five mutants are shown in Table 3. The specifically induced cells were prepared by adding either L-tryptophan or L-kynurenine to $0.005 \mathrm{M}$ in a culture growing at the expense of asparagine, and harvesting the organisms $3 \mathrm{hr}$ later.

With respect to pyrrolase and formamidase synthesis, the two $\mathrm{Ky}^{-}$mutants showed the same qualitative responses as did the wild type to induction by tryptophan and kynurenine: both these compounds served as inducers, and possessed more or less equal effectiveness. The $\mathrm{Py}^{-}$mutants and the Fo- mutant showed entirely different qualitative responses; in these mutants, tryptophan did not induce measurable synthesis of any of the first three enzymes of the pathway, whereas kynurenine was an effective inducer for all of them. Py- and $\mathrm{Fo}^{-}$mutants share a common metabolic property which differentiates them from both wild-type and $\mathrm{Ky}^{-}$organisms; namely, inability to generate kynurenine from tryptophan within the organism, as a result of the genetic elimination of one of the two enzymes which catalyse this conversion.

Since the $\mathrm{Py}^{-}$mutants are unable to synthesize the first enzyme of the pathway, they cannot initiate oxidative attack on $\mathrm{L}$-tryptophan. The failure of $\mathrm{x}$-tryptophan to act as an inducer for these mutants therefore shows that tryptophan itself does not possess inductive function. In the Fo- mutant, L-tryptophan can presumably undergo a slow endogenous conversion to L-formylkynurenine, as a result of the retention of basal pyrrolase activity in this phenotype. The absence of induction by tryptophan therefore provides indirect evidence that L-formylkynurenine is not 
an effective inducer for either pyrrolase or kynureninase. Taken in conjunction, the data obtained with the $\mathrm{Py}^{-}$and $\mathrm{Fo}^{-}$phenotypes accordingly demonstrate that L-kynurenine is the only early member of the metabolic pathway which possesses inductive function, and that it can serve simultaneously as the inducer of pyrrolase, formamidase, and kynureninase.

Table 3. Levels of early enzymes of the aromatic pathway in $\mathrm{Py}^{-}, \mathrm{Fo}^{-}$, and $\mathrm{Ky}^{-}$ mutants of Pseudomonas fluorescens

Organisms were grown for $3 \mathrm{hr}$ in liquid mineral asparagine medium, unsupplemented and supplemented with L-tryptophan or L-kynurenine at an initial concentration of $0.005 \mathrm{~m}$. The activities, determined on cell-free extracts, are expressed as $\mathrm{m} \mu$ moles of substrate decomposed/min./mg. protein.

\begin{tabular}{|c|c|c|c|c|}
\hline \multirow[b]{2}{*}{ Strain } & \multirow{2}{*}{$\begin{array}{c}\text { Addition to } \\
\text { basal medium }\end{array}$} & \multicolumn{3}{|c|}{ Enzyme assayed* } \\
\hline & & Pyrrolase & Formamidase & Kynureninase \\
\hline $\mathbf{P y}-\mathbf{3 4}$ & $\begin{array}{l}\text { None } \\
\text { Tryptophan } \\
\text { Kynurenine }\end{array}$ & - & $\begin{array}{r}4 \\
4 \\
375\end{array}$ & $\begin{array}{c}\leqslant 0 \cdot 1 \\
\leqslant 0 \cdot 1 \\
47\end{array}$ \\
\hline $\mathbf{P y}^{-54}$ & $\begin{array}{l}\text { None } \\
\text { Tryptophan } \\
\text { Kynurenine }\end{array}$ & - & $\begin{array}{r}3 \\
4 \\
173\end{array}$ & $\begin{array}{l}\leqslant 0 \cdot 1 \\
\leqslant 0 \cdot 1 \\
30\end{array}$ \\
\hline $\mathrm{Fo}^{-16}$ & $\begin{array}{l}\text { None } \\
\text { Tryptophan } \\
\text { Kynurenine }\end{array}$ & $\begin{array}{l}1 \cdot 0 \\
0 \cdot 5 \\
9\end{array}$ & - & $\begin{array}{l}\leqslant 0 \cdot 1 \\
\leqslant 0 \cdot 1 \\
49\end{array}$ \\
\hline $\mathrm{Ky}^{-12}$ & $\begin{array}{l}\text { None } \\
\text { Tryptophan } \\
\text { Kynurenine }\end{array}$ & $\begin{array}{l}0 \cdot 3 \\
19 \\
18\end{array}$ & $\begin{array}{r}3 \\
49 \\
54\end{array}$ & - \\
\hline $\mathbf{K y}-\mathbf{2 1}$ & $\begin{array}{l}\text { None } \\
\text { Tryptophan } \\
\text { Kynurenine }\end{array}$ & $\begin{array}{l}0 \cdot \tau \\
39 \\
37\end{array}$ & $\begin{array}{r}6 \\
131 \\
160\end{array}$ & - \\
\hline Wild type & $\begin{array}{l}\text { None } \\
\text { Tryptophan } \\
\text { Kynurenine }\end{array}$ & $\begin{array}{l}0 \cdot 4 \\
21 \\
20\end{array}$ & $\begin{array}{r}3 \\
51 \\
53\end{array}$ & $\begin{array}{l}\leqslant 0 \cdot 1 \\
74 \\
60\end{array}$ \\
\hline
\end{tabular}

* The symbol - has been used in the column that refers to the genetically deleted enzyme of each mutant. In no case was activity of the genetically deleted enzyme detectable, either with or without induction.

It is noteworthy that, in the $\mathbf{P y}^{-}$mutants, genetic elimination of the ability to synthesize pyrrolase did not prevent the synthesis of formamidase by asparaginegrown organisms; the basal amount of this enzyme in the $\mathrm{Py}^{-}$mutants was in the normal wild-type range. This fact makes improbable the simplest explanation for the existence of basal pyrrolase and formamidase activities; namely, endogenous synthesis of the inducer (kynurenine) at a very low rate. So far as is known, kynurenine is biosynthesized uniquely from tryptophan through the action of pyrrolase and formamidase; consequently, the genetic elimination of either enzyme should completely prevent the intracellular formation of kynurenine. The relatively high basal values of pyrrolase and formamidase found here are thus best interpreted as the result of an imperfect mechanism of repression, rather than of a continuous endogenous production of inducer.

The inductive responses of the mutants showed some curious quantitative anomalies. One is the induced hyperproduction of formamidase characteristic of mutant $\mathrm{Py}^{-} \mathbf{3 4}$ and, in lesser measure, of mutant $\mathbf{P y}-$ 54. Both mutants showed specific 
formamidase activities following induction with kynurenine which are far above the range for the wild type, whereas the basal values of this enzyme in asparagine-grown mutant organisms was normal. In mutant $\mathrm{Ky}^{-} \mathbf{2 1}$, the basal and the induced values of pyrrolase and formamidase were approximately double those characteristic of the wild type.

\section{Kinetic evidence for the role of kynurenine as primary inducer}

If the interpretation offered above for the inductive responses of $\mathrm{Py}^{-}$and $\mathrm{Fo}^{-}$ mutants is correct, it follows that in wild-type organisms exposure to kynurenine should result in an immediate triggering of induction, whereas exposure to tryptophan should lead to a slight delay in the initiation of induction, corresponding to the time required for the endogenous generation of an effective inducing concentration of kynurenine. This led us to make a more refined analysis of the early kinetics of induction in the wild type by tryptophan and kynurenine. The results of several such experiments showed that the early rate of synthesis of kynureninase and formamidase by the wild type was always markedly lower in response to induction by tryptophan than in response to induction by kynurenine. There was, in fact, an absolute lag of variable duration (10-20 $\mathrm{min}$.) before induction by tryptophan became detectable, whereas induction by kynurenine was always detectable within 5-10 min. The critical measurements must be made on extracts of low enzyme content, where the errors of assay are maximal, so that the values for specific activities are relatively unreliable. However, experiments of this type always gave the same general result. Typical data are shown in Fig. 3.

\section{The inductive affinity of L-kynurenine and of non-metabolizable analogues}

Since L-kynurenine was not metabolized by $\mathrm{Ky}^{-}$mutants, the rate of synthesis of pyrrolase and formamidase as a function of inducer concentration could be measured with this phenotype. Organisms were induced by growth for $6 \mathrm{hr}$ in mineral asparagine containing a series of concentrations of $L$-kynurenine. The results (Fig. 4) show that maximal amounts of both pyrrolase and formamidase were induced by $3 \times 10^{-5} \mathrm{M}$-kynurenine, and detectable induction occurred even with $3 \times 10^{-6} \mathrm{M}$-kynurenine. This extraordinarily high affinity no doubt explains why induction of the wild type following exposure to L-tryptophan is initiated with so brief a lag.

The discovery that L-kynurenine, but not L-tryptophan, acted as the inducer for the synthesis of pyrrolase, formamidase, and kynureninase, led us to examine analogues of L-kynurenine as possible non-metabolizable inducers. Two chemically related compounds which cannot be detectably metabolized by the wild type are the $\mathrm{D}$-isomer and the product of borohydride reduction, $\gamma$-DL-hydroxy-L-kynurenine. These compounds were accordingly tested for their inductive effect on the wild type. As shown in Fig. 5, synthesis of pyrrolase, formamidase, and kynureninase was induced by $\gamma$-hydroxy-L-kynurenine, although its affinity was far lower than that of L-kynurenine: a concentration of $3 \times 10^{-3} \mathrm{M}$ was required to induce maximal amounts of pyrrolase and formamidase. D-Kynurenine likewise induced the synthesis of all three enzymes, the saturating inducer concentration being approximately $10^{-3} \mathrm{M}$ (Table 4).

Neither D-kynurenine nor $\gamma$-hydroxy-L-kynurenine induced measurable forma- 
tion of pyrocatechase and lactonizing enzyme by wild-type organisms. This finding is in accordance with the evidence that at least one sequential inductive step occurs below the level of kynurenine. The absence of these two enzymes shows that the inductive effects of $\mathrm{D}$-kynurenine and $\gamma$-hydroxy-L-kynurenine are not attributable to contamination by $\mathrm{L}-\mathrm{kynurenine.}$

These experiments reveal, with much greater clarity than any other type of analysis, the strict co-ordination between the differential rates of synthesis of pyrrolase and formamidase: at all inducer concentrations, the ratio between the specific activities of the two enzymes remains constant, within the limits of error of the

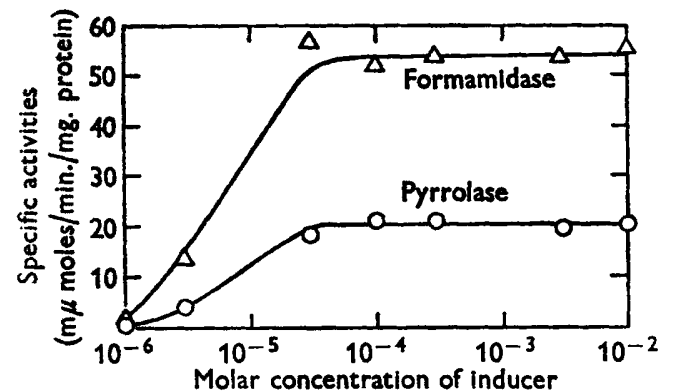

Fig. 4

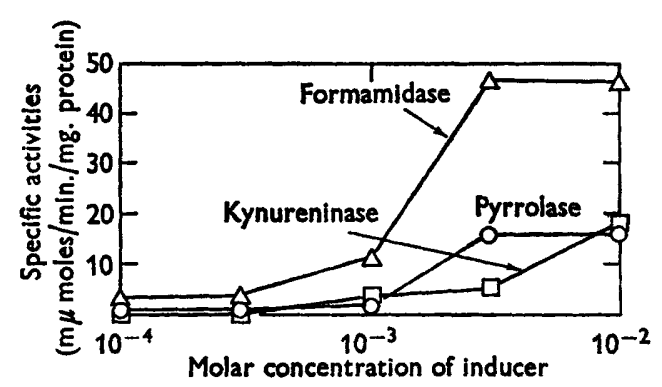

Fig. 5

Fig. 4. The specific activities of pyrrolase and formamidase induced in a kynureninase-less mutant $\left(\mathrm{Ky}^{-12}\right)$ of Pseudomonas fluorescens by growth in the presence of different concentrations of $\mathbf{L}$-kynurenine.

Fig. 5. The specific activities of pyrrolase, formamidase, and kynureninase induced in the wild type of Pseudomonas fluorescens by growth in the presence of different concentrations of $\gamma$-hydroxy-L-kynurenine, a non-metabolizable inducer.

\section{Table 4. Induction of Pseudomonas fluorescens wild type by D-kynurenine}

Organisms were harvested after growth for $6 \mathrm{hr}$ in an asparagine mineral medium, supplemented with the indicated concentrations of $\mathbf{D}-\mathbf{k y n u r e n i n e}$.

$\begin{array}{lccc}\text { Concentration of } & \overbrace{\text { Pyrrolase }}^{\text {Formamidase Kynureninase }} \\ \text { D-kynurenine (M) } & \overbrace{\text { Specific activities of extracts }}^{\text {Enzyme }} \\ \text { None } & \mathbf{0 \cdot 4} & \mathbf{3} & \leqslant 0 \cdot 1 \\ 10^{-5} & \mathbf{0 \cdot 3} & \mathbf{4} & \leqslant 0 \cdot 1 \\ 10^{-4} & \mathbf{2} & \mathbf{1 7} & \mathbf{2} \\ 5 \times 10^{-4} & \mathbf{2 4} & \mathbf{7 2} & \mathbf{3 4} \\ 10^{-8} & \mathbf{3 0} & \mathbf{8 9} & \mathbf{5 2}\end{array}$

assays. As shown by the data on induction of the wild type with $\gamma$-hydroxy-Lkynurenine and D-kynurenine, this co-ordination does not extend to include kynureninase. The inductive affinity of the kynureninase-forming system for both non-metabolizable inducers was far lower than that of the system responsible for the formation of pyrrolase and formamidase. This fact implies that kynurenine and its analogues play two distinct roles in induction, acting separately to induce the syntheses of pyrrolase and formamidase on the one hand, and of kynureninase on the other. 


\section{Patterns of induction in other strains}

The peculiar mechanism of induction of pyrrolase, formamidase, and kynureninase demonstrated for Pseudomonas fluorescens strain Tr-28 might be a strain-specific property, not shared by other pseudomonads which oxidize tryptophan through the aromatic pathway. To obtain information on this point, the inductive responses of two other Pseudomonas strains, RYs-2 and RYs-3, were examined. Like strain Tr-23, these strains were originally isolated from soil by enrichment with tryptophan as carbon source; but the three strains were obtained on different occasions from different samples of soil, so that a close genetic relationship between them is improbable. Strain RYS-3 is a fluorescent pseudomonad; RYs-2 does not produce pigment. The patterns of synthesis of pyrrolase, formamidase, and kynureninase by organisms grown at the expense of asparagine, L-tryptophan and L-kynurenine as sole carbon sources are shown in Table 5.

Table 5. Patterns of synthesis of early enzymes on the aromatic pathwayby Pseudomonas strains RYS-2 and RYS-B

\begin{tabular}{|c|c|c|c|c|}
\hline \multirow{2}{*}{ Strain } & \multirow{2}{*}{$\begin{array}{l}\text { Substrate } \\
\text { for growth }\end{array}$} & \multicolumn{3}{|c|}{ Enzyme } \\
\hline & & $\begin{array}{c}\text { Pyrrolase } \\
\text { Specific } \\
\text { substrate }\end{array}$ & $\begin{array}{l}\text { Formamidas } \\
\text { activities, } \mathrm{m} \mu \mathrm{m} \\
\text { lecomposed } / \mathrm{mi}\end{array}$ & $\begin{array}{l}\text { Kynureninase } \\
\text { es of } \\
\text { lmg. protein }\end{array}$ \\
\hline RYS-2 & $\begin{array}{l}\text { Asparagine } \\
\text { L-Tryptophan } \\
\text { L-Kynurenine }\end{array}$ & $\begin{array}{l}0 \cdot 1 \\
29 \\
21\end{array}$ & $\begin{array}{l}0 \cdot 23 \\
46 \\
36\end{array}$ & $\begin{array}{c}\leqslant 0 \cdot 1 \\
84 \\
102\end{array}$ \\
\hline RYS-3 & $\begin{array}{l}\text { Asparagine } \\
\text { L-Tryptophan } \\
\text { L-Kynurenine }\end{array}$ & $\begin{array}{c}\leqslant 0.05 \\
10 \\
9\end{array}$ & $\begin{array}{l}0 \cdot 15 \\
102 \\
58\end{array}$ & $\begin{array}{l}\leqslant 0 \cdot 1 \\
77 \\
57\end{array}$ \\
\hline
\end{tabular}

The patterns of enzyme synthesis by strain RYs-2 were qualitatively indistinguishable from those of strain Tr-23: L-tryptophan and L-kynurenine induced all three enzymes to approximately equal degrees; asparagine-grown pseudomonads contained measurable amounts of pyrrolase and formamidase, but not of kynureninase. The basal specific activities found in strain RYS-2 were significantly lower than those found in strain Tr-23, whereas the specific activities of induced organisms were approximately the same. For strain RYs-3, kynurenine also served as an inducer of all three enzymes, although the amounts were slightly lower than those induced by tryptophan. In strain RYs-3, no pyrrolase activity was detected in asparagine-grown organisms, although there was a very low amount of formamidase. If pyrrolase were really absent, the inductive mechanism which operated in strain Tr-23 obviously did not operate in strain RYs-3. However, the basal pyrrolase amount may have been too low to be detected by present assay methods. It is perhaps significant that strain RYs-3 has a very long growth lag (about $10 \mathrm{hr}$ ) on transfer from a medium containing asparagine to one containing tryptophan as sole carbon source; under the same conditions, strain Tr-23 has a growth lag of only $2 \mathrm{hr}$. 


\section{DISCUSSION}

The mechanisms which regulate synthesis of the inducible enzymes that catalyse the early steps in the bacterial oxidation of tryptophan have proved to be unexpectedly varied and complex. The original hypothesis (Suda et al. 1949; Stanier \& Tsuchida, 1949) of strict sequential induction was evidently an oversimplified one; sequential inductions do occur, but by no means all the enzymes of the pathway are sequentially induced. Pyrrolase, formamidase, and kynureninase, the first three enzymes of the pathway, are all synthesized in response to a single inducer, L-kynurenine. At first sight, this might suggest that the synthesis of these three enzymes is under the control of a single operon, which can be de-repressed by kynurenine. The syntheses of pyrrolase and formamidase show close co-ordination under all conditions of induction, so that the assumption of control through a single operon may be correct for these two enzymes. Co-ordination does not extend to kynureninase, however, as shown particularly clearly by the lesser affinity of its induction by the non-metabolizable kynurenine analogue, $\gamma$-hydroxy-L-kynurenine. Accordingly, it appears probable that kynurenine has two different sites of action as an inducer.

L-Tryptophan, the primary substrate in this metabolic pathway, is not able to induce the synthesis of any of the early enzymes, as shown by experiments with mutants that lack either pyrrolase or formamidase. Nevertheless, exposure of uninduced organisms of the wild type to L-tryptophan causes a rapid initiation of enzyme synthesis. This inductive effect is an indirect one, made possible because the uninduced organisms have relatively high basal amounts of pyrrolase and formamidase. Exposure to an exogenous supply of tryptophan thus permits an immediate endogenous synthesis, although at a low rate, of the actual primary inducer, L-kynurenine. Since kynureninase, the enzyme responsible for conversion of kynurenine to anthranilic acid and alanine, is undetectable in uninduced organisms, the kynurenine so formed can accumulate. Its affinity for induction of pyrrolase and formamidase is exceptionally high, and an accelerated rate of synthesis of these two enzymes consequently begins 10-15 min. after exposure of organisms to tryptophan. The non-co-ordinate sequential induction of kynureninase is also rapidly initiated, with the result that, $30-60 \mathrm{~min}$. after exposure to the primary substrate, the cells possess the enzymatic equipment to convert tryptophan to anthranilic acid at a high rate. Anthranilic acid oxidase, the next enzyme of the sequence, appears to be sequentially induced by its substrate. Unfortunately, there is no easy and sensitive assay for this enzyme, so that we have been unable to study its specific synthesis. However, cells that have acquired an effective complement of the first three enzymes of the pathway as a result of brief exposure to tryptophan cannot oxidize anthranilic acid at an appreciable rate, which indicates that there is a substantial time-lag, following exposure to the primary substrate, before the sequential induction of anthranilic acid oxidase is initiated. The existence of a very marked time-lag in synthesis has been shown by direct enzymatic analysis for the next two enzymes of the pathway, pyrocatechase and lactonizing enzyme.

Recent studies (Stanier, Hegeman \& Ornston, in the press) have clarified the mechanism of induction of the enzymes responsible for the oxidation of mandelic acid by Pseudomonas fluorescens. This biochemical pathway converges at the level 
of catechol with the aromatic pathway for tryptophan oxidation. None of the enzymes of the mandelate sequence can be detected in uninduced cells. The initial induction is co-ordinate, and results in the synthesis of the first five enzymes of the pathway, responsible for the conversion of D-mandelic acid to benzoic acid. This multiple induction is elicited by D-mandelic acid, the primary substrate, as shown by studies with the appropriately blocked mutant. Hence the initial inductive events in the metabolically convergent mandelate and tryptophan pathways are mechanistically different, even though their gross physiological consequences are analogous.

Induction by the primary substrate has such obvious adaptive value in the regulation of a dissimilatory pathway that it is tempting to look for a special explanation of the 'metabolite induction' which controls synthesis of the first enzymes in the pathway for the dissimilation of tryptophan. Unlike many of the oxidizable substrates used by Pseudomonas fluorescens, L-tryptophan also has a general role in the metabolism of the cell. It is synthesized endogenously to serve as a precursor for protein synthesis. In the absence of an external supply of tryptophan, the organism must accordingly prevent loss of its limited internal biosynthetic supply of this amino acid as a result of oxidation through the dissimilatory pathway. Since the later enzymes of the dissimilatory pathway cannot be detected in asparaginegrown organisms, it is evident that the control mechanisms do in fact operate to prevent such loss. The first two enzymes of the pathway are present in low amounts in uninduced organisms, which might suggest that some of the endogenous tryptophan supply is diverted to the formation of kynurenine, the specific inducer of these enzymes. This interpretation is excluded, however, by the finding that the basal amount of formamidase remains unchanged in mutants which have lost the ability to form pyrrolase, and are thus incapable of converting tryptophan to kynurenine. The basal amounts of pyrrolase and formamidase are thus best interpreted as resulting from a slightly defective repressor, rather than from endogenous production of inducer. Although there are no data on the size of the tryptophan pool in $P$. fluorescens, analyses of the amino acid pools in other micro-organisms indicate that the tryptophan is one of the least abundant constituents, frequently being undetectable chromatographically. The primary physiological factors which channel endogenously synthesized tryptophan to protein synthesis in $\boldsymbol{P}$. fluorescens are therefore probably: (1) maintenance of a low pool concentration; (2) extremely high affinity of the specific activating enzyme. Given these two conditions, no appreciable flow to kynurenine should occur, even though the organism contains pyrrolase and formamidase. However, if the concentration of the endogenous tryptophan pool occasionally rises transiently to a value at which pyrrolase can compete with the activating enzyme for their common substrate, the brief lag in inductive response that is introduced by metabolite induction would serve as a damper on synthesis of the enzymes of the aromatic pathway. Only a high and steadily maintained pool concentration, resulting from the presence of a high exogenous concentration of tryptophan, would trigger effectively their induction. 
This work was supported by research grants to R. Y. Stanier from the National Institutes of Health and the National Science Foundation. The authors wish to thank Miss Margaret MacPherson for help in the isolation of mutants, and Dr M. Doudoroff and Mr G. Hegeman for helpful criticism.

One of the authors, N.J.P., was a Fellow of the Consejo Nacional de Investigaciones Científicas y Técnicas, Argentina. Permanent address: Department of Microbiology, University of Cuyo, Mendoza, Argentina.

\section{REFERENCES}

Berrman, E. J. (1962). Tryptophan metabolism in Pseudomonas. Nature, Lond. 196, 150. Cohen-Bazire, G., Sistrom, W. R. \& Stanier, R. Y. (1957). Kinetic studies of pigment synthesis by non-sulfur purple bacteria. J. cell. comp. Physiol. 49, 25.

Hayaishi, O. \& Sranier, R. Y. (1951). The bacterial oxidation of tryptophan. III. Enzymatic activities of cell-free extracts from bacteria employing the aromatic pathway. J. Bact. 62, 691.

Hayaishi, O. \& Stanier, R. Y. (1952). The kynureninase of Pseudomonas fluorescens. J. biol. Chem. 195, 735.

JACOB, F. \& MONOD, J. (1961). Genetic regulatory mechanisms in the synthesis of proteins. J. molec. Biol. 3, 318.

Karlsson, J. L. \& Barker, H. A. (1948). Evidence against the occurrence of a tricarboxylic acid cycle in Azotobacter agilis. J. biol. Chem. 175, 913.

Katagiri, M. \& Hayaishi, O. (1956). Enzymatic degradation of $\beta$-ketoadipic acid. Fed. Proc. 15, 285.

KNox, W. E. (1955). Methods in Enzymology. Ed. by S. P. Colowick \& N. O. Kaplan, vol. 2, p. 246. New York: Academic Press.

Srstrom, W. R. \& Stanier, R. Y. (1954). The mechanism of formation of $\beta$-ketoadipic acid by bacteria. J. biol. Chem. $210,821$.

STANIER, R. Y. (1947). Simultaneous adaptation: a new technique for the study of metabolic pathways. J. Bact. 54, 339.

Stanier, R. Y. \& HaYaishi, O. (1951). The bacterial oxidation of tryptophan: a study in comparative biochemistry. Science, 114, 326.

Stanier, R. Y., HAYaishi, O. \& Tsuchida, M. (1951). The bacterial oxidation of tryptophan. I. A general survey of the pathways. J. Bact. 62, 355.

Stanier, R. Y. \& Tsuchida, M. (1949). Adaptive enzymatic patterns in the bacterial oxidation of tryptophan. J. Bact. 58, 45.

Suda, M., Ha Yaishi, O. \& Oda, Y. (1949). Studies on enzymatic adaptation. I. Successive adaptation, with special reference to the metabolism of tryptophan. Symposium on Enzyme Chemistry, 1, 79.

TANaka, T. \& KNox, W. E. (1958). The nature and mechanism of the tryptophan pyrrolase (peroxidase-oxidase) reaction of Pseudomonas and rat liver. J. biol. Chem. 234, 1162. 